\title{
An Unusual Case of Primate Arterial Pattern in a Human Upper Limb
}

\author{
Un Caso Inusual de Patrón Arterial de Primates en un Miembro Superior Humano
}

Crótida de la Cuadra-Blanco; Jorge Murillo-González; Elena Martínez-Sanz \& José Ramón Mérida-Velasco

DE LA CUADRA-BLANCO, C.; MURILLO-GONZÁLEZ, J.; MARTÍNEZ-SANZ, E. \& MÉRIDA-VELASCO, J. R. An unusual case of primate arterial pattern in a human upper limb. Int. J. Morphol., 38(4):963-969, 2020.

SUMMARY: During routine undergraduate dissections of the upper limb, variations on the usual arterial and muscular patterns were observed in a 68 year-old male cadaver. The arterial and muscular pattern found in our specimen is similar to that of some primates in the following terms. 1) Brachial artery duplicity, on the right side, with a superficial brachio-ulnoradial artery. 2) In the right upper limb, the biceps brachii muscle continued with the superficial muscles of the forearm. 3) The brachial artery on the left side, cross over in front of the median nerve, as the only artery of the arm with a network axillary pattern. 4) On both sides, the ulnar artery was superficial and originated at the elbow from superficial brachial arteries. 5) The right anterior interosseous artery intervened in the vascularization of the hand. These results suggest that this may be a case of early detention of human embryonic development and/or the persistence of phylogenetic older patterns. In the literature, we have found no reference to the presence of all these variations in the same individual. The objective of our study was to analyze these variations from an embryological and phylogenetic perspective.

KEY WORDS: Superficial arteries; Upper limb; Variation; Development; Embryology.

INTRODUCTION

Different authors (Adachi, 1928; McCormack et al., 1953; Fuss et al., 1985; Rodríguez-Baeza et al., 1985; Rodríguez-Niedenführ et al., 2003) have systematized variations in the arterial pattern of the upper limb. Majority of these variations occur in radial artery followed by ulnar artery, while variations in the brachial artery are less common (Chakravarthi et al., 2014).

A detailed knowledge of variations of branching pattern of vessels is essential for providing accuracy during vascular diagnosis and reconstructive surgery and also in evaluation of angiographic images (Chakravarthi et al.).

In man, the brachial artery is unique and is situated profound to the median nerve. However, during embryonic development in both humans and primates there is a brachial artery situated superficial to the median nerve, which constitutes the main vessel of the arm (Manners-Smith, 1910; de Garis \& Swartley, 1928; Ikeda et al., 1988). Senior (1926) identified the superficial brachial artery in human embryos of $21 \mathrm{~mm} \mathrm{CR}$ length, which anastomosed, with the brachial artery in human embryos of $23 \mathrm{~mm} \mathrm{CR}$ length.
Adachi defined the superficial branchial artery as the artery that runs superficial to the median nerve. When present, the superficial brachial artery may replace the main brachial artery trunk completely or may be accompa-nied by an equally important, more important or less important brachial artery trunk running deep to the median nerve (Khullar, 2014).

The terminology used to refer to superficial arteries of the upper limb is summarized in Fig. 1.

Our study is based on the description of the arterial patterns of both upper limbs of a cadaver. The arterial pattern is analysed from embryological, phylogenetic and clinical perspectives.

\section{MATERIAL AND METHOD}

Our cadaveric material proceeds from routine undergraduate dissections at the Department of Anatomy and 
Embryology of our University. This is a 68 year-old embalmed male cadaver from the Department's deposit obtained following the legal procedures governing the donation of bodies.

Vessels were measured with a pair of sliding calipers, usually applied at the site of vascular origin.

The nomenclature used corresponds to the English version of the Terminologia Anatomica of the Federative International Programme for Anatomical Terminology (Federative International Programme for Anatomical Terminology, 2011). Superficial arteries were denominated using a modified version of the terminology of RodríguezNiedenführ et al. (2003) (Fig. 1).

\section{RESULTS}

The results of our findings summarised in Figure 2 and the abbreviations in Table I.

Right upper limb. The axillary artery, below the median nerve roots, bifurcated into the brachial artery and the su- perficial brachial artery ( 4.5 and $5.5 \mathrm{~mm}$ caliber, respectibly from its origin). While the superficial brachial artery at the elbow fossa divided into the radial and the superficial ulnar arteries, the brachial artery hence termed as the common interosseous artery.

The superficial brachial artery emitted no branches in the arm; the brachial artery emitted the usuall branches (Fig. 3).

The radial artery ( $3.3 \mathrm{~mm}$ caliber) ran deep to a muscular expansion of the biceps brachii muscle, wich continued with some of the superficial forearm muscles, and was found in the usual position in the forearm. The ulnar artery $(3 \mathrm{~mm}$ caliber) was deep to biceps aponeurosis and lay anterior to the antebrachial musculature. The palmaris longus muscle was the only muscle of the forearm to cross anterior to the ulnar artery, characteristic of superficial brachioulnar arteries (Fig. 4).

The biceps brachii muscle presented a muscular expansion, which continued with the folowing superficial muscles of the forearm: pronator teres, flexor carpi radialis and flexor digitorum superficialis muscles. Only the palmaris longus and flexor carpi ulnaris muscles arose at the level of the medial epicondyle (Fig. 5).

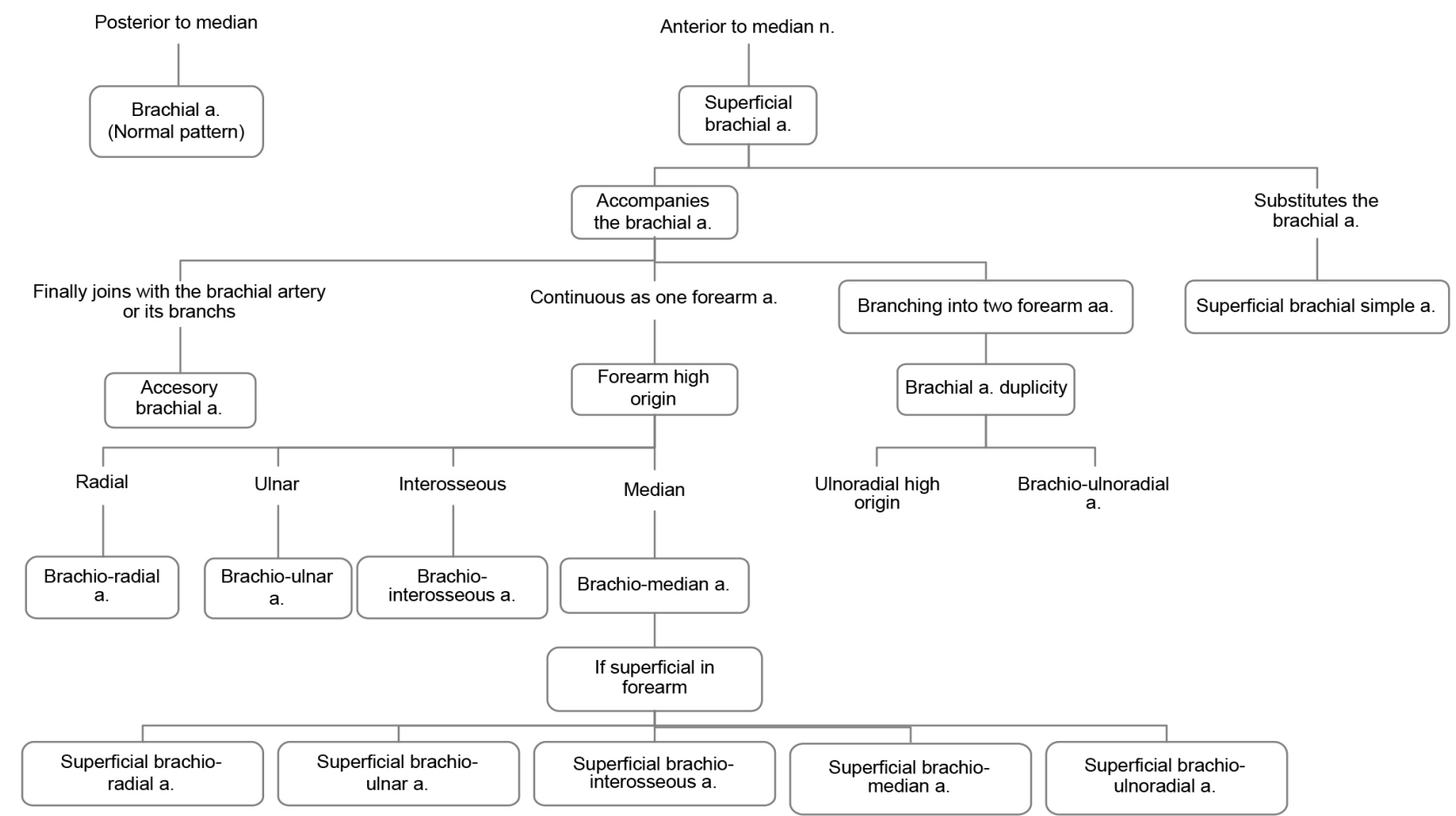

Fig. 1. Terminology used to describe the arterial variations of the upper limb (based and modificated on the criteria proposed by Rodríguez-Niedenführ et al, 2003). 
Table I. abbreviations of the anatomical structures.

\begin{tabular}{llll}
\hline \multicolumn{2}{l}{ ABBREVIATIONS } & & \\
\hline AIA & anterior interosseous artery & MN & median nerve \\
AN & axillary nerve & PB & palmar brachial artery \\
BA & brachial artery & PBA & profunda brachii artery \\
BB & biceps brachii muscle & PL & palmaris longus \\
BR & brachio-radialis muscle & PT & pronator teres muscle \\
CHA & circunflex humeral artery & RA & radial artery \\
CIA & common inter osseous artery & RN & radial nerve \\
CSA & circunflex scapular artery & SBA & superficial brachial artery \\
FCR & flexor carpi radialis & SUA & superficial ulnar artery \\
FCU & flexor carpi ulnaris & SUCA & superior ulnar collateral artery \\
FDP & flexor digitorum profundus & UN & ulnar nerve \\
FDS & flexor digitorum superficialis & & \\
\hline
\end{tabular}

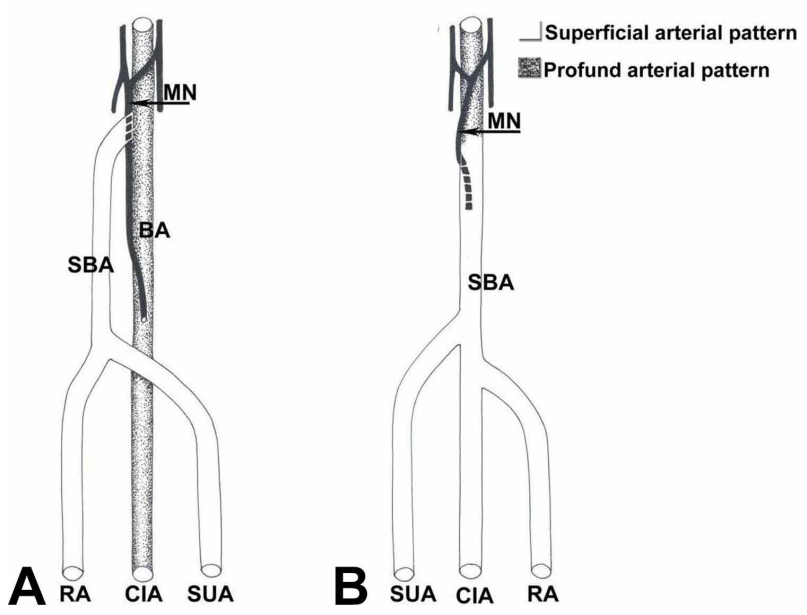

Fig. 2. Summary of our results. Right upper limb (A) and left upper $\operatorname{limb}(\mathrm{B})$.
The brachial artery continued to the elbow fossa, hence termed the common interosseous artery. This artery, of $3.5 \mathrm{~mm}$ caliber from its origin, divided into the anterior and posterior interosseous arteries and emitted small muscular branches (Fig. 5). The median nerve in the forearm and hand presented a normal arrangement and was not accompanied by the median artery.

In the hand, the superficial palmar arch was incomplete and was predominantly ulnar. The anterior interosseous artery (1.2 $\mathrm{mm}$ caliber) had anastomotic connection with the arteries of the deep palmar arch (Fig. 6).

Left upper limb. On the left side, the third portion of the axillary artery formed two trunks. 1) Superior of larger caliber (3.2 mm caliber from its origin) for it was the origin

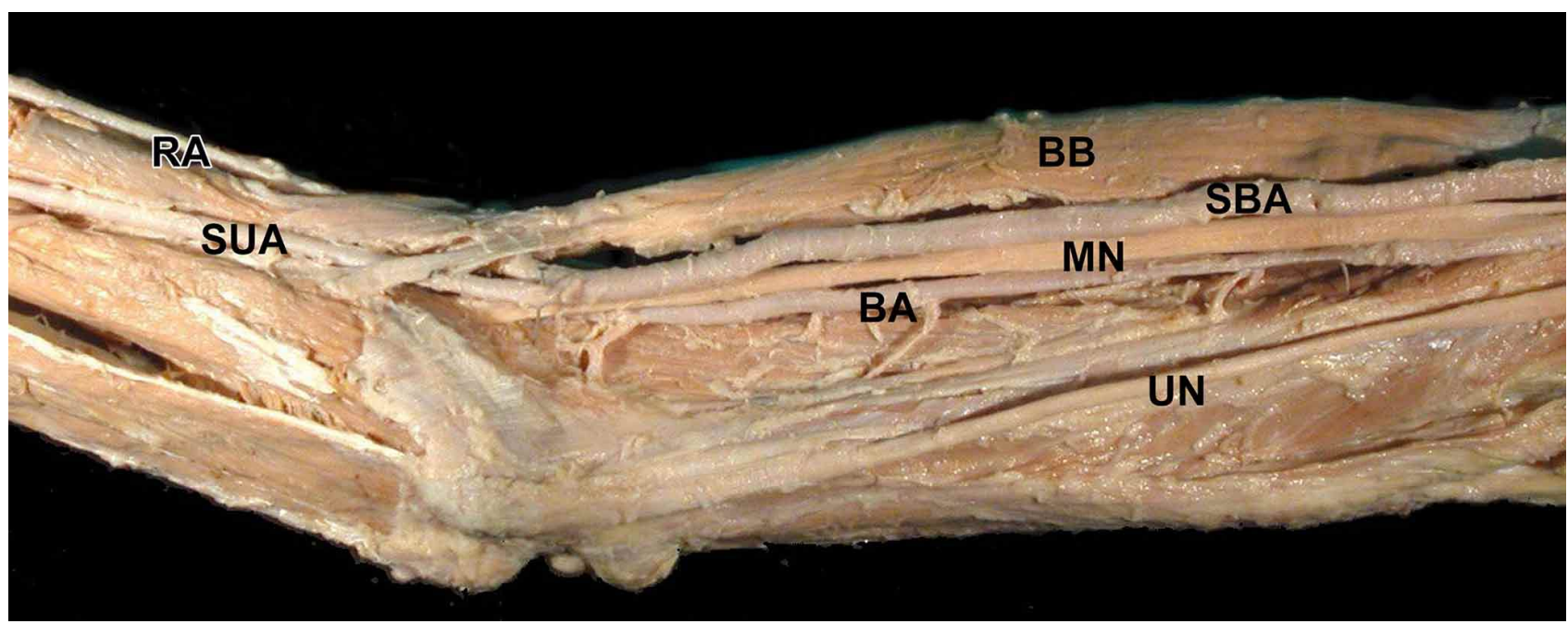

Fig. 3. Medial view of the right arm. Two brachial arteries are observed. Whereas the superficial brachial artery does not emit collateral branches, the brachial artery emits branches for the neighboring muscles. 

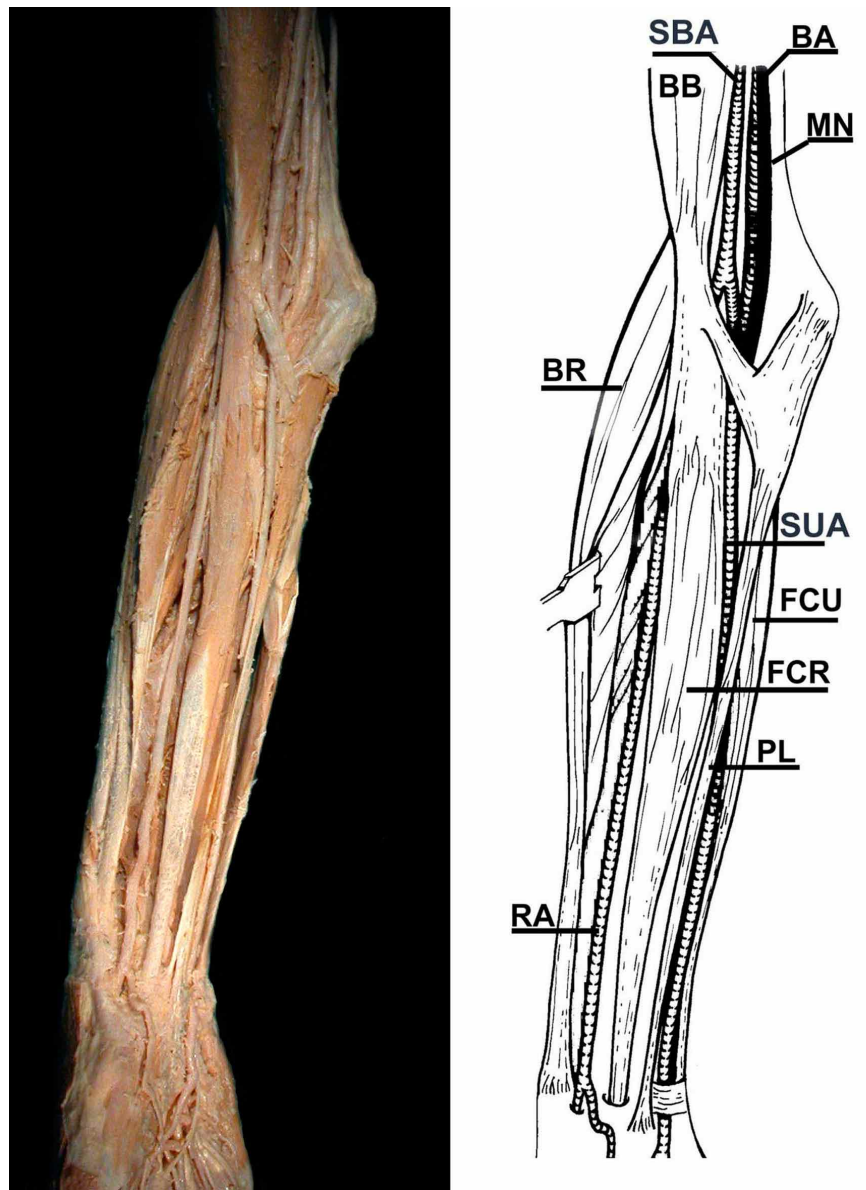

Fig. 4. Anterior view of the right's elbow and forearm. In the elbow fossa the two brachial arteries run profound the bicipital aponeurosis and the superficial brachial artery is divided into superficial ulnar artery and radial artery. The biceps brachii muscle is continuous with pronator teres, flexor carpi radialis and flexor digitorum superficialis muscles. Palmaris longus muscle crosses over in front of the ulnar artery.
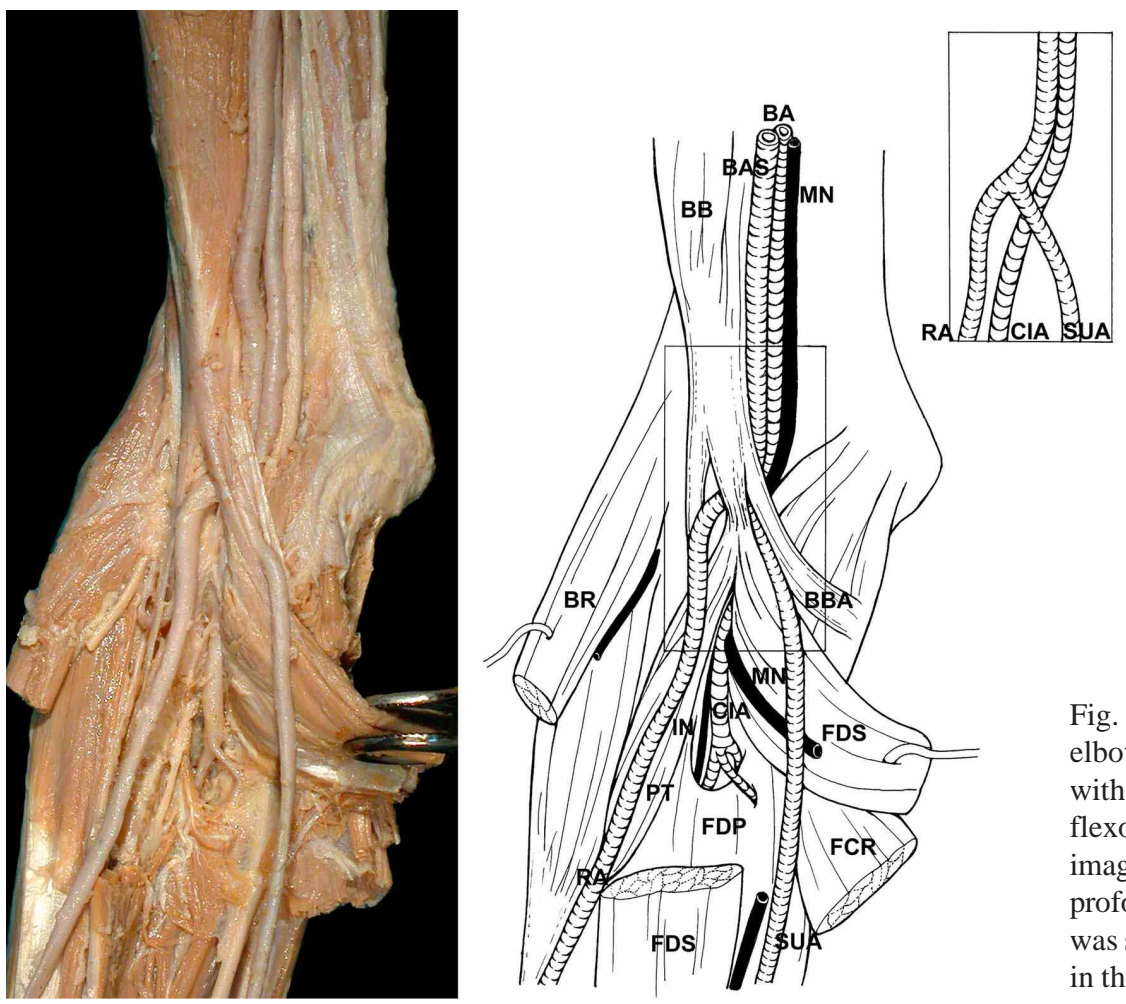

Fig. 5. Anterior view of the right arm around the elbow. The biceps brachii muscle is continuous with the pronator teres, flexor carpi radialis and flexor comun superficial muscles (sectioned in the image) by an expansion. The radial artery proceeds profound this muscular expansion. The ulnar artery was superficial while the brachial artery continued in the forearm as the common interosseous artery. 

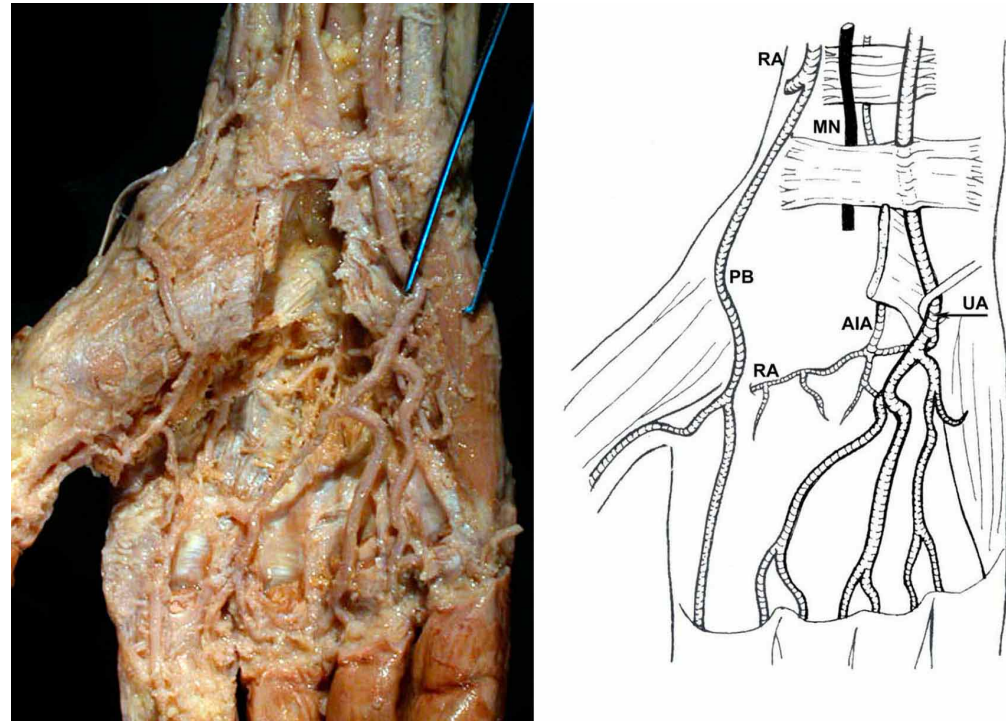

Fig. 6. Palmar view of the right hand: the superficial palmar arch is incomplete and mainly ulnar. The anterior interosseous artery has anostomotic connection with the arteries of the deep palmar arch.

Fig. 7. Branches of the left axillary artery. The left axillary artery emits two trunks: superior that is the origin of the circunflex scapular, circumflex humeral and profunda brachii arteries; inferior where the superior ulnar collateral artery originates. of the circunflex scapular, circumflex humeral and profunda brachii arteries. 2) Inferior ( $2.5 \mathrm{~mm}$ caliber from its origin) from where the superior ulnar collateral artery and muscular branches originated. The inferior trunk is continued with the superficial brachial artery (Fig. 7).

The brachial artery in its superficial course had no collateral branch and was posterior to the bicipital aponeurosis divided into the superficial ulnar artery and the radio-interosseous trunk. The three divided arteries had a caliber of around 4 $\mathrm{mm}$ from their origin.

The left superficial ulnar artery was superficial to biceps aponeurosis and, in the forearm, had a similar arrangement on the right side (Fig. 8).

The radio-interosseous trunk divided into the radial and the common interosseous arteries, which emitted recurrent arteries of large caliber, $1.5 \mathrm{~mm}$ from its origin. The disposition of the radial and common interosseous arteries in the forearm conformed to the usual pattern.

On this side, the superficial palmar arch was similar to the right side. The deep palmar arch had a normal arrangement.

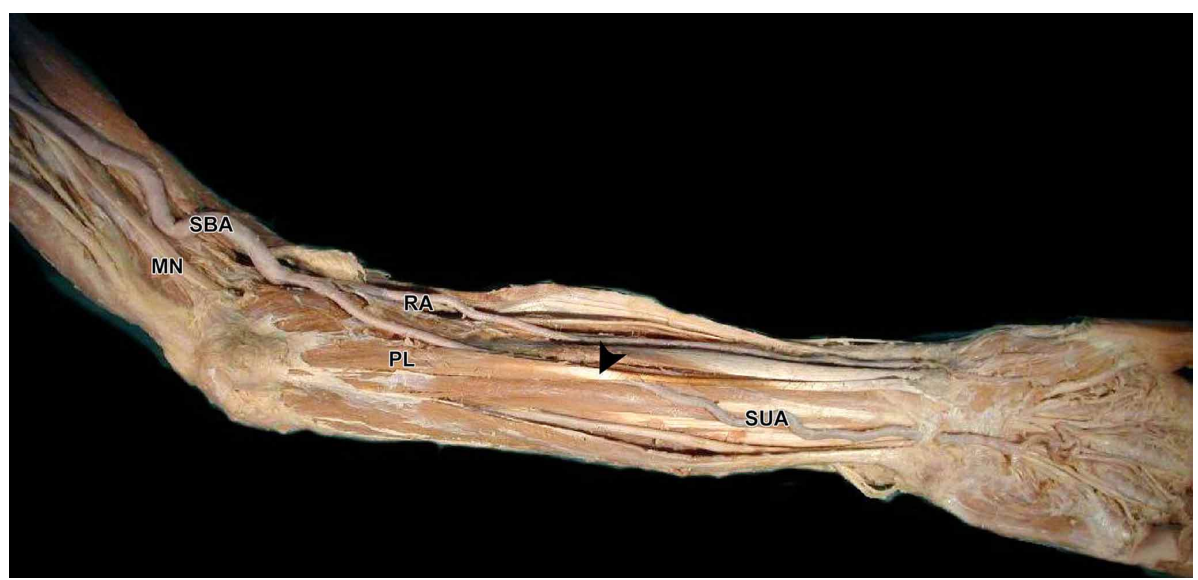

Fig. 8. Medial view of the left arm and anterior view of the left forearm: The left brachial artery was superficial to the median nerve and in the cubital fossa divided into the superficial ulnar artery and radial-interosseous trunk. The superficial ulnar artery in the middle third of the forearm is only crossed by the palmaris brevis muscle (arrowhead). 


\section{DISCUSSION}

The arterial patterns found in this specimen are rare. In the literature, we have found no reference to the presence of all these variations in the same individual.

In humans, the incidence of brachial artery duplicity ranges from 0.3-1.07 \% (McCormack et al.; Rodríguez-Baeza et al.; Rodríguez-Niedenführ et al., 2003). The superficial brachial artery most frequently originates from the upper third of the brachial artery (Rodrígez-Niedenführ et al., 2001).

According to Rodriguez-Niedenführ et al. (2001), the superficial brachial simple artery in humans has an incidence ranging from 3.6-9.6\%. It is usually unilateral (Fuss et al.) and originates below the median nerve roots (Pabst \& Lippert, 1968; Rodríguez-Baeza et al.; RodríguezNiedenführ et al., 2001), although for Fuss et al. the artery becomes superficial above the median nerve roots.

With respect the bifurcation of the superficial brachial artery observed on the left upper limb, into the superficial ulnar artery and the radio-interosseous trunk, only Narayanan \& Murugan (2018) reported a similar case of bifurcation of the brachial artery.

Our dissection also revealed that the superficial ulnar artery was bilateral, originated at the elbow and was deep to biceps aponeurosis on the left upper limb and superficial on the right. The presence of the superficial ulnar artery seems to be a rare variation, with an incidence of 0.7-7 \% reported in the literature (Dartnell et al., 2007). Superficial ulnar artery variations have been reported in unilateral and bilateral limbs, with bilateral cases observed more often in females (Natsis et al., 2006). Pabst \& Lippert termed this occurrence "the superficial ulnar forearm artery" and reported an incidence of $1 \%$, as in the case of McCormack et al. and Fuss et al. Whereas the first two authors held that the artery proceeded from a brachial artery duplicity, Fuss et al. claimed that it originated from a superficial brachial simple artery.

The current ontogenetic explanation for the presence of superficial arteries is based on the appearance of a superficial vascular system, which simultaneously branches and maintains connections at different levels with the deeper system. The direction of the blood flow would determine the regression or agenesia of one of the systems depending on the hemodynamic requirements of the developing musculature (Rodriguez-Baeza et al.).

The biceps brachii muscle has been described as a brachial-antebrachial muscle in gorillas (Testut, 1884; Le
Double, 1897). This muscular arrangement increases the prehensile strength in primates. This muscular disposition in man has disappeared owing to the evolution of the hand movements and the reduction of forearm movements (Testut).

According to Ikeda et al., the arterial pattern of the upper limb in Lorisiforms (prosimiae, primates) is similar to the arrangement of these vessels in specimens of 21 to 23 $\mathrm{mm} \mathrm{CR}$ length in human embryo development.

However, Matsumoto et al. (1994) believe that arterial development in the upper limb undergoes important changes in primates (Tupaia) in comparison to man. For these authors, the superficial brachial artery is a transient developmental condition closely related to the development of the radial artery. However, in our study the superficial arteries observed were not related to the isolated origin of the radial artery.

The deep disposition of the radial artery with regard to the biceps brachii muscle, as described in this study, has been observed by Kumar (2004). However, the case of Kumar revealed a biceps brachii muscle of normal characteristics, which is quite unlike the case described in the present study.

We consider that the right side of our disection is a very early detention of embryonic development since the anterior interosseous artery intervened in the vascularization of the hand (Singer, 1933). In vascularization of the hand in lower primates, the interosseous artery is joined to the radial artery and to the ulnar artery (Manners-Smith), as occurs in our right deep palmar arch.

The intervention of the anterior interosseous artery in formation of the deep palmar arch was also observed in humans by Jurjus et al. (1986) and Keen (1961). Poteat (1986) described a case of a very early detained development with absence of the radial artery, in which the interosseous artery was the main artery of the hand.

The association of a superficial brachial artery and network arterial pattern in the axillary artery is normal in primates and rare in man (Manners-Smith; De Garis \& Swartley; Ikeda et al.). For Fuss et al., in humans, this axillary network pattern may correspond to the brachial artery in regression.

For this reason, we believe that some cases described as brachial artery duplicity may correspond to a superficial brachial simple artery in which the brachial artery involutes persisted as arterial branches with common origin. 
These results suggest that this may be a case of early detention of human embryonic development and/or the persistence of phylogenetic older patterns. In the literature, we have found no reference to the presence of all these variations in the same individual.

\section{ACKNOWLEDGMENTS}

We thank to all those people who anonymously, altruistically and in solidarity donate their body to science. Without his valuable gesture, it would not have been possible to carry out this work. The authors wish to express their gratitude to Mr. Richard Smithson, for the English editing of this manuscript.

DE LA CUADRA-BLANCO, C.; MURILLO-GONZÁLEZ, J.; MARTÍNEZ-SANZ, E. \& MÉRIDA-VELASCO, J. R. Un caso inusual de patrón arterial de primates en un miembro superior humano. Int. J. Morphol., 38(4):963-969, 2020.

RESUMEN: Durante las disecciones de pregrado de rutina del miembro superior, se observaron variaciones en los patrones arteriales y musculares habituales en un cadáver macho de 68 años. El patrón arterial y muscular que se encuentra en nuestro espécimen es similar al de algunos primates en los siguientes términos. 1) Duplicidad de la arteria braquial, en el lado derecho, con una arteria braquioulnoradial superficial. 2) En el miembro superior derecho, el músculo bíceps braquial continuó con los músculos superficiales del antebrazo. 3) La arteria braquial en el lado izquierdo, se cruza frente al nervio mediano, como la única arteria del brazo con un patrón axilar en red. 4) En ambos lados, la arteria ulnar era superficial y se originó en el codo de las arterias braquiales superficiales. 5) La arteria interósea anterior derecha intervino en la vascularización de la mano. Estos resultados sugieren que este puede ser un caso de detención temprana del desarrollo embrionario humano y/o la persistencia de patrones filogenéticos más antiguos. En la literatura, no hemos encontrado ninguna referencia a la presencia de todas estas variaciones en el mismo individuo. El objetivo de nuestro estudio fue analizar estas variaciones desde una perspectiva embriológica y filogenética.

PALABRAS CLAVE: Arterias superficiales; Miembro superior; Variación; Desarrollo; Embriología.

\section{REFERENCES}

Adachi, B. Das Arteriensystem der Japaner. Vol. I, part I, Kyoto, Maruzen, 1928 pp.234-7.

Chakravarthi, K. K.; Ks, S.; Venumadhav, N.; Sharma, A. \& Kumar, N. Anatomical variations of brachial artery - its morphology, embryogenesis and clinical implications. J. Clin. Diagn. Res., 8(12):AC17-20, 2014

Dartnell, J.; Sekaran, P. \& Ellis, H. The superficial ulnar artery: incidence and calibre in 95 cadaveric specimens. Clin. Anat., 20(8):929-32, 2007.

De Garis, C. F. \& Swartley, W. B. The axillary artery in white and negro stocks. Am. J. Anat., 41(2):353-97, 1928.
Federative International Programme for Anatomical Terminology (FIPAT). Terminologia Anatomica. Stuttgart, Thieme, International Federation of Associations of Anatomists, 2011.

Fuss, F. K.; Matula, C. W. \& Tschabitscher, M. Die arteria brachialis superficialis. Anat. Anz., 160(4):285-94, 1985.

Ikeda, A.; Miyake, S.; Ikeda, K. \& Hayama, S. Three-dimensional analysis of the arterial pattern of the upper limbs in Lorisiformes (Prosimiae, Primates).Acta Anat. (Basel), 132(4):297-303, 1988.

Jurjus, A.; Sfeir, R. \& Bezirdjian, R. Unusual variation of the arterial pattern of the human upper limb. Anat. Rec., 215(1):82-3, 1986.

Keen, J. A. A study of the arterial variations in the limbs, with special reference to symmetry of vascular patterns. Am. J. Anat., 108:245-61, 1961.

Khullar, M. Superficial brachial artery: its embryological and clinical significance. Indian J. Clin. Pract., 24(10):925-8, 2014.

Kumar, M. R. Multiple arterial variations in the upper limb of a South Indian female cadaver. Clin. Anat., 17(3):233-5, 2004.

Le Double, A. F. Traité des Variations du Système Musculaire de l'Homme et de leur Signification au Point de Vue de l'Anthropologie Zoologique. Tome Premier. Paris, Librairie C. Reinwald Schleicher Frères Editeurs, 1897. pp.84-5.

Manners-Smith, T. The limb arteries of primates. J. Anat. Physiol., 45(Pt. 1):23$64.11,1910$.

Matsumoto, S.; Kuhn, H. J.; Vogt, H. \& Gerke, M. Embryological development of the arterial system of the forelimb in Tupaia. Anat. Rec., 240(3):416-22, 1994.

McCormack, L. J.; Cauldwell, E. W. \& Anson, B. J. Brachial and antebrachial arterial patterns; a study of 750 extremities. Surg. Gynecol. Obst., 96(1):43$54,1953$.

Narayanan, S. \& Murugan, S. Bifurcation of brachial artery into a common radialinterosseous trunk and superficial ulnar artery: a rare variation. Anat. Sci. Int., 93(3):400-3, 2018.

Natsis, K.; Papadopoulou, A. L.; Paraskevas, G.; Totlis, T. \& Tsikaras, P. High origin of a superficial ulnar artery arising from the axillary artery: anatomy, embryology, clinical significance and a review of the literature. Folia Morphol. (Warsz.), 65(4):400-5, 2006.

Pabst, R. \& Lippert, H. Bilateral occurrence of a. brachialis superficialis, a. ulnaris superficialis and a. mediana. Anat. Anz., 123(2):223-6, 1968.

Poteat, W. L. Report of a rare human variation: absence of the radial artery. Anat. Rec., 214(1):89-95, 1986

Rodríguez-Baeza, A.; Nebot, J.; Ferreira, B.; Reina, F.; Pérez, J.; Sañudo, J. R. \& Roig, M. 1995. An anatomical study and ontogenetic explanation of 23 cases with variations in the main pattern of the human brachio-antebrachial arteries. J. Anat., 187(Pt. 2):473-9, 1985.

Rodríguez-Niedenführ, M.; Vázquez, T.; Nearn, L.; Ferreira, B.; Parkin, I. \& Sañudo, J. R. Variations of the arterial pattern in the upper limb revisited: a morphological and statistical study, with a review of the literature. J. Anat., 199(Pt. 5):547-66, 2001.

Rodríguez-Niedenführ, M.; Vázquez, T.; Parkin, I. G. \& Sañudo, J. R. Arterial patterns of the human upper limb: Update of anatomical variations and embryological development. Eur. J. Anat., 7(S1):21-8, 2003.

Senior, H. D. A note on the development of the radial artery. Anat. Rec., 32:220-1, 1926.

Singer, E. Embryological pattern persisting in the arteries of the arm. Anat. Rec., 55(4):403-9, 1933

Testut, L. Les Anomalies Musculaires Chez L'Homme Expliquées Par L'Anatomie Comparée. Leur importance en anthropologie. Paris, G. Masson, Editeurs, 1884. Pp.388-95.

\section{Corresponding author:}

Jorge Murillo-González

Department of Anatomy and Embryology

Faculty of Medicine, Complutense

University of Madrid, 28040

Madrid - SPAIN

ORCID ID: 0000-0002-3455-2378

Email: jmurillo@ucm.es

Received: 11-02-2020

Accepted: 27-03-2020 